\title{
Enhancing Creativity by Using NLP(Neurological- Linguistic Programming) and Guided Imagery
}

\author{
Shoshana Rosemarin ${ }^{1,2}$ \\ ${ }^{1}$ Department of Behavioral Sciences, Ariel University, Israel \\ ${ }^{2}$ Department of Special Education, Talpiot College, Israel
}

Copyright (C2016 by authors, all rights reserved. Authors agree that this article remains permanently open access under the terms of the Creative Commons Attribution License 4.0 International License.

\begin{abstract}
The significance of the role of creativity as an essential component of giftedness has long been assumed by most of the experts in the field. The most fertile creations will often be those formed of elements drawn from domains which are far apart. It is assumed that creativity is a personality variable, and not an ability, and thus it is believed that all students have creative potential that can be identified and nurtured. Imagery, intuition and unconscious activity are found to be associated with the essence and the nurturance of creativity. Whereas conscious thought may be focused and convergent, unconscious thought may be more associative and divergent. Moreover, while a thought or answer is fully activated if it is both conscious and accessible, it is deeply activated if it is accessible but not currently conscious. Education tries to reach its goals by creating strategies of approach rather than by trying to understand, support and develop the child's enormously rich inner life. Based on all of the above insights, the article will focus on the introduction of NLP (Neurological-Linguistic Programming) which originated in the 1970 ' by Bandler and Grinder. Besides its general use as a means to modifying undesirable behaviors, NLP offers modeling tools by which the gifted student can identify specific, reproducible patterns in the language and behavior of effective role models, especially the most creative ones - like Albert Einstein.
\end{abstract}

Keywords Creativity, NLP, Imagery, Role Model

\section{The Essence of Creativity}

Creativity is defined $[1, \mathrm{p} .48]$ as "A process in which the human mind seems to borrow least from the exterior world", while making "new combinations of associative elements which are useful. The most fertile will often be those formed of elements from domains which are far apart" [2, p.912].

The capacity to approach the world with an open and creative attitude, more than anything else, makes the individual feel that life is worth living. This idea is expressed by the saying: "I create, therefore I am" [3, p.63]

The relationship between intelligence and creativity is often discussed and investigated. While Intelligence tests call for answers that require convergent thinking, creativity calls for divergent thinking. Thinking that is in the nature of searching and readiness to pursue different directions, [3, p.461].

Creativity is multi-faceted. Emotion and intellect, freedom and discipline, reason and intuition, the precise and the gossamer, primary and secondary processes, chaos and order - all of these apparent opposites can exist in creative harmony in the human brain $[4$, p.70]. Moreover, the integration of these functions is necessary to actualize the potential of any one function. [4, p. 155].

\section{Characteristics of a Creative Person}

Creativity is a personality variable, and not an ability [5]. Studies of personality characteristics of highly creative individuals have resulted in lists of hundreds of descriptors, which contain items that overlap and, at times, contradict one another.

The following characteristics could represent those lists: curiosity, freedom from inhibitions and stereotyped thinking, an internal locus of evaluation, freedom of symbolic expression, endlessly questing new challenges and solutions, [6, p.300] tolerance for ambiguity [7], and imagination [8].

It is agreed that no one person can be expected to exhibit all the characteristics that appear in the literature, nor will an individual necessarily exhibit them all the time. [6, p. 304].

In addition to the fact that creativity is a function of the interaction between cognition and personality, it is also a function of the interaction with the environment. A psychological safe environment reduces inappropriate external evaluation while communicating empathic understanding [6, p. 303]. 


\section{Who can be Creative?}

Based on brain research it is proposed that "The ultimate creative capacity of the brain may be, for all practical purposes, infinite" [5, p 69]. Since everyone solves problems - simple, mundane, everyday problems, it is assumed that all students have creative potential. Moreover, "it is well established that an individual's creativity can be improved through instruction" [6, p. 308]. The level at which one is functioning provides a starting point for determining the educational programming that helps develop the student's natural creative abilities [9].

Moreover, "There is a strong likelihood that creativity does not need to be developed in man, but simply liberated" $[4$, p. 70$]$.

\section{Conscious / Unconscious Thought}

According to the unconscious thought theory," conscious thought is adept to analytic and derivative processing that primarily isolates and discriminates, but unconscious thought excels at integrating and associating information and is capable of carrying out associative searches across a broad range of background knowledge" [2, p. 913]. Therefore, one could say that unconscious thought is more "liberal" than conscious thought and leads to the generation of items or ideas that are less obvious, and more creative.

Moreover, conscious thought can ruin the search for creative solutions, and novel connections or ideas often insinuate themselves into the conscious mind when conscious attention is directed elsewhere [2]. This idea can be metaphorically demonstrated by saying that "whereas conscious thought stays firmly under the searchlight, unconscious thought ventures out to the dark and dusty nooks and crannies of the mind" [10, p. 138].

Thus, it is recommended that "upon being confronted with a task that requires a certain degree of creativity, it pays off to delegate the labor of thinking to the unconscious mind" [10, p. 145].

It is assumed that a thought or answer is fully activated if it is both conscious and accessible, but deeply activated if it is accessible but not currently conscious. [11]. Somerset Maugham, the famous writer, developed this concept by saying that "the writer has to allow the unconscious its full activity which is somewhat pompously known as inspiration" $[12, \mathrm{p} .13]$.

It is important to note that the products of unconscious thought may not always be immediately entered into consciousness. Instead, they may remain unconscious, emerging into consciousness as insight at a later time. [2].

\section{Giftedness, Creativity and Unconsciousness}

Creativity holds a crucial role in Renzulli's model of giftedness. He suggests that "history tells us that it has been the creative and productive people of the world, the producers rather than consumers of knowledge, the reconstructionists of thought in all areas of human endeavor, that have become recognized as truly gifted individuals" [13, p. 21].

Yet, it should be noted that even the most talented and creative people have to invest long hours of hard work on the way to their great achievements. The mastery of any skill-whether a routine daily task or a highly refined talentdepends on the ability to perform it unconsciously with speed and accuracy, while consciously carrying on other brain functions [14, p.70]. The long hours of practice and learning in the talent field are necessary for the development of automaticity in the many subskills, required to reach top-level performance in that talent field [14, p.72]. Some processes, especially in sports and cognitive fields are done so rapidly under automatic control that the same individual could not even come close to this rate under conscious control [14, p. 74].

\section{Imagery / Visualization}

Imagery is defined as a type of sensory experience, in which images arise, independent of external stimulation. It is not restricted to the visual mode alone, but can stimulate sound, taste, smell, and touch [4].

Though it is believed that "We all possess the world's finest multi-sensory teaching machine right inside our own heads", it should be noted that eidetic imagery, a type of three-dimensional imagery, which often occurs in children, tends to disappear as we get older. It persists in only a few highly imaginative adults and is associated with the sudden flash of insight [4, p. 66].

In any case, regardless of the domain, imagery appears useful in the creative process and is, in fact, a major component of flexibility in thinking in fact imagery has been reported to provide greater flexibility than verbal techniques in a variety of problem solving situations [4, p. 409].

Several successful uses of imagery have been demonstrated:

1. As a substitute for actual practice in performing some activity.

2. As stand-in for perceptual stimulation, producing effects such as those evoked when subjects actually view a stimulus.

3. As a part of an individual's reasoning skills $[4, \mathrm{p}$. 408].

Imagery is especially useful regarding the nurturance of the gifted. Since the gifted adolescents are especially able to project the future and to evaluate the emotional satisfactions, personal identity and specialized roles a career may involve, they can significantly benefit from imagery when thoughts of future goals and careers begin to be explored [4, p. 409]. Moreover, probability guessing, which plays a crucial role in any scientific work, is an activity that brings the intuitive 
function into the learning process $[4$, p. 410$]$.

\section{NLP and the Modeling Process}

NLP was originated by Bandler and Grinder in the 1970', based on the patterns of language and behavior they had discovered in the works of three exceptional therapists: Fritz Perls (founder of Gestalt therapy); Virginia Satir (founder of family and systematic therapy), and Milton Erickson (founder of the American society of Clinical Hypnosis). As a result of their earlier work, Grinder and Bandler formalized their modeling techniques and their own individual contributions under the name "Neuro-Linguistic Programming" to symbolize the relationship between the brain, language and the body [15, p. 203].

According to NLP, the basic process of change involves -finding out what the present state of the person is, and then adding the appropriate resources to lead that person to the desired state [15, p.204].

The objective of the modeling process is not to end with the one right or true description of a particular person's thinking process, but rather to make an 'instrumental map' that enables the application of the strategies that have been modeled in an effective way [15, p.155].

From an NLP perspective the manifestation of genius is a function of unique mental strategies and other cognitive patterns and characteristics, which can be learned. Even if a person has innate talents and creative abilities, they will not become manifest without effective strategies, skills and support. People who do not naturally possess certain thinking abilities can develop them by learning more effective strategies. Moreover, the goal should be to grasp the strategies and models for finding the strategies of exceptional individuals and making practical models out of those strategies $[15, \mathrm{p}$. xvii].

In his book series Strategies of Genius (vols. I-III) Dilts sums up his study of the strategies of a number of well-known geniuses, among them are Einstein, Mozart, Leonardo de Vinci, Walt Disney, Nikola Tesla, Aristotle, Sigmund Freud and Arthur Conan Doyle's Sherlock Holmes. Since Albert Einstein is not only acknowledged around the world as a genius ,but has practically become the symbol for genius, the focus of the present article is to extract the strategies of Einstein's thinking and use them as a model for enhancing creativity that should lead to influential discoveries and invention [15, p. xi].

Einstein claimed that, "The whole of science is nothing more than a refinement of everyday thinking" [16, p. 290]. Like NLP Einstein related the basic process of everyday thinking to the stimulation and reactivation of sensory experience [15, p. 47]. He claimed that "Even the concept of the 'real external world' of everyday thinking rests exclusively on sense impressions" [16, p. 290].

Einstein felt that the underlying laws of the universe were not random or statistical and that we must not give up the search for simple but broad rules defining the basic relationships between things [15, p. 3]. This is why he strove to find the underlying order beneath phenomena and experience which seemed inexplicable. In order to achieve that goal, he would form a symbolic visual metaphor of some real world phenomenon and then questioning the assumptions presupposed by that symbolic construction [15, p. 71]. Imaging was the most important part of his thinking strategy. "It provides a bridge between purely abstract logical symbols and words, and the 'chaotic diversity of our sense-experience" " $[15$, p. 77]. Einstein pointed out that "Atomic theory could be viewed more as a visualizing symbol than as knowledge concerning the factual construction of matter" [17, p. 19].

This notion is stressed by Hunt as a general statement, saying that "important components in developing intuitive ability are imagery, fantasy, and visualization" [18].

Moreover, Einstein claims that "our thinking creates problems that the same type of thinking will not solve" $[15, \mathrm{p}$. 29]. His recommendation is to look for new ways of thinking, or in other words - to be creative and not to rely only on the familiar types of thinking.

"Through the modeling technique of NLP, we can gain new insights into the thought patterns and processes that contributed to Einstein's special genius in a way that can make them more available to us. By uncovering some of the underlying micro elements of his thinking strategy, we can better understand and more easily transfer his creative ability" $[15$, p. 46].

\section{Applying Einstein's Strategy}

The basic elements of his thinking process can be summarized in seven steps:

1. Begin with a sensory experience.

2. Identify the fundamental elements in the system to be modeled.

3. Use constructed visual images to represent these basic elements.

4. Begin to freely engage in "combinatory play" with the elements, switching back and forth between the different frames of reference.

5. Move to a broader "visual survey" that encompasses the other systems or perceptual positions (third position).

6. Make an explicit description of the "generating rules" that have been seen of felt from the "third position"

7. Use the generating rules to make new predictions which can then be tested against the evidence of sensory experience.

If our goal is to enhance the creativity of the potentially gifted, we should remember that the strategy for how one thinks about information is at least as important as the content of the information [15, p. 186].

In NLP we could focus on the sensory structures at the base of Einstein's thinking process, rather than on the results 
of that process (mathematics or physics). This is conducted while being led to a relaxation state, using guided visualization, encouraging the use of intuition, and communicating with the unconscious. The goal of the process is to bring to the internalization of Einstein's strategies, and thus trying to walk in his footsteps.

\section{REFERENCES}

[1] Miller,A.I. (2007). Unconscious Thought, Intuition, and Visual Imagery-A Critique of "Working Memory, Cerebellum, and Creativity", Creativity Research Journal, v. 19, n. $1,47-48$.

[2] Zhong, C., Dijksterhuis, A., \& Galinsky,A. (2008). The Merits of Unconscious Thought in Creativity, Psychological Science, 19, 912-918.

[3] Horner, A. J. (2006). The Unconscious and the Creative Process, Journal of the American Academy of Psychoanalysis and Dynamic Psychiatry, 34, 3.

[4] Clark, B. (1988).Growing Up Gifted, Columbus, Ohio: Merrill Publishing Company.

[5] Esyenck, H. J. (1997). Creativity and Personality. In M. A. Runco (Ed.) The Creativity Research Handbook: v 1 (pp. 41-66). Cresskill, NJ: Hampton Press.

[6] Selbey, E. D., Shaw, E. J., \& Houtz, J. C., (2005). The Creative Personality, Gifted Child Quarterly, v. 49, n. 4.

[7] Dacey, J. S. (1989). Discriminating Characteristics of the Families of Highly Creative Adolescents. Journal of Creative
Behavior, 23, 263-271.

[8] Feist, G. J. (1999). The Influence of Personality on Artistic and Scientific Creativity. In R.J. Sternberg (Ed.), Handbook of Creativity (pp. 273-296). New York: Cambridge University Press.

[9] Treffinger, D. J., et al. (2004). Enhancing and Expanding Gifted Programs: The levels of Service Approach. Waco, TX: Prufrock Press.

[10] Dijksterhuis, A, \& Meurs, T. (2006). Where Creativity Resides: The Generative Power of Unconscious Thought, Consciousness and Cognition, 15, 135-146.

[11] Wegner, D. M., \& Smart, L. (1997). Deep Cognitive Activation: A new approach to the Unconscious. Journal of Consulting and Clinical Psychology, 65, 984-995.

[12] Maugham, W. S. (1993). A writer's Notebook (p.13). New York: Penguin. (Original work published 1949, New York: Doubleday).

[13] Renzulli, J. S. \& Reis, S. M., (1985). The Schoolwide Enrichment Model: A Comprehensive Plan for Educational Excellence, Creative Learning Press.

[14] Bloom, B. S. (1986). Educational Leadership, (pp. 70-77).

[15] Dilts, R. B. (1994), Strategies of Genius, Volume II, Albert Einstein, Capitola, Ca: Meta Publications.

[16] Einstein, A. (1954). "Physics and Reality" in Ideas and Opinions, Crown Books, New York, NY.

[17] Einstein, A. (1949). "Autobiographical Notes" Albert Einstein, Philosopher-Scientist by Paul Arthur Schilpp, Northwestern University Press, Evanston.

[18] Hunt, M. (1982). The universe within. New York: Simon \& Schuster. 